\title{
Relações entre fenomenologia e memória: possíveis reflexões sobre a exclusão social em bibliotecas públicas
}

Relations between memory and phenomenology: possible reflections about social exclusion in public libraries

Ana Claudia Perpétuo de Oliveira da Silva

Doutoranda em Ciência da Informação na Universidade Federal de Santa Catarina - UFSC. Docente no Departamento de Ciência da Informação da Universidade Federal de Santa Catarina - UFSC. E-mail: anacpo72@gmail.com

\section{Resumo}

O texto propõe uma reflexão sobre a questão da exclusão social em ambientes e serviços de bibliotecas públicas. Através de um formato de ensaio, da visão de mundo fenomenológica e extração do componente "memória" neste contexto, objetiva suscitar a reflexão de âmbito filosófica destacando pensamentos acerca da exclusão. Ressalta questões relativas à memória como transcendência da "morte" e o acúmulo de conhecimento e, a partir deste enfoque, traça possíveis relações com as práticas de profissionais atuantes nas bibliotecas públicas, de caráter ético e político, como a exclusão social.

Palavras-chave: Fenomenologia. Memória. Escrita. Bibliotecários. Exclusão social.

\begin{abstract}
:
The text proposes a reflection on the issue of social exclusion in public libraries environments and services. Through a test format, the phenomenological world view and the component extraction "memory" in this context, aims to raise the philosophical framework of reflection highlighting thoughts about the exclusion. Highlights issues relating to memory as transcendence of "death" and the accumulation of knowledge and, from this perspective, outlines possible relationships with the professionals working practices in public libraries, ethical and political nature, such as social exclusion.
\end{abstract}

Key-words: Phenomenology. Memory. Writing. Librarians. Social exclusion. 


\section{Introdução}

"Qual o limite de nossa fuga?"

(F.C. Souza)

Não muito raro, as ideias quando chegam até mim encontram lembranças e associações no contexto da arte, especialmente da música, um dos campos de minha formação e apreço. Passado o incômodo inicial da pergunta que inaugura este ensaio, ecoaram em minha memória as fugas de Bach. Musicalmente, "fuga" é um estilo de composição marcante da música barroca, tem como característica a imitação, a repetição do tema por vozes que se sobrepõem ao entrar em diferentes tempos da música, sucessivamente (inicialmente eram também chamados cânones).

Mas, embora seja possível imaginar alguma relação, não é desta fuga que trata Souza. Essa pergunta é "recortada" da coluna que o autor assina no Infohome", ao comentar sobre a falta de posicionamento da classe de bibliotecários diante do déficit de cidadania que existe em nosso país e pela sensação aparente de 'não se importar' (esta expressão é fruto da minha interpretação) com as sucessivas indicações à presidência da Fundação Biblioteca Nacional, que não levam em consideração a escolha de um profissional da área de Biblioteconomia.

Quando da reflexão sobre a pergunta, encontro possíveis caminhos de entendimento para tentar compreender, qual seria o "limite da fuga". Quantas dúvidas! Flusser (2011) dedicou um livro (e vários artigos) para tratar o tema da dúvida que designou como "um estado de espírito polivalente". Em dose exagerada, a dúvida paralisa a atividade mental, mas moderadamente, estimula o pensamento. Associada à curiosidade, é o berço da pesquisa.

Tentando utilizar estes questionamentos de forma equilibrada, como sugere Flusser, este ensaio é pensado e escrito para profissionais atuantes em bibliotecas, bibliotecários ou não, formalmente atuantes na esfera pública ou não, partindo do pressuposto de que todos os indivíduos (incluindo os que compõem esta atividade profissional), impreterivelmente, fazem parte da esfera pública e sua participação atenta neste contexto é salutar e necessária para a busca de um equilíbrio social. Entretanto, intenciona provocar mais precisamente profissionais atuantes em bibliotecas públicas ao abordar questões de exclusão social que permeiam estes espaços.

\footnotetext{
${ }^{1}$ Boletim em ambiente virtual criado pelo Prof Dr Oswaldo Francisco de Almeida Júnior dedicado a assuntos relacionados às bibliotecas e bibliotecários. Disponível em: <www.ofaj.com.br〉. Acesso em: 29 abr. 2013.
}

InCID: R. Ci. Inf. e Doc., Ribeirão Preto, v. 7, n. 1, p. 29-42, mar./ago. 2016. 
No texto, a relação desta questão com a fenomenologia e memória se dá inicialmente destacando o valor da memória no contexto fenomenológico (que serve de pano de fundo, escolha da visão de mundo deste estudo) e, posteriormente, ressaltando pontos relevantes relativos à memória fundamentais para as reflexões que se deseja abordar.

Estes pontos - a transcendência da "morte" e o acúmulo de conhecimento - são duas características da memória que servem de base para a discussão seguinte, relacionada às práticas de profissionais que atuam em bibliotecas públicas, de caráter ético e político, como a exclusão social (problema identificado em trabalhos no campo de Ciência da Informação).

O objetivo das relações estabelecidas no texto foi instigar (através da escrita, este mecanismo de memória) a reflexão em torno do posicionamento ético-político destes profissionais, tomando como evidência a questão da exclusão social nos ambientes de bibliotecas públicas. $\mathrm{O}$ estabelecimento da visão de mundo fenomenológica e a extração do componente "memória" neste contexto, se justifica, pois, que se encaixa no propósito de levar à contemplação do tema, da reflexão de âmbito filosófica ao destacar pensamentos acerca da exclusão.

Considero, finalizando, que a visão de mundo estabelecida pela fenomenologia e sua abordagem através do componente memória podem contribuir para as reflexões (e porque não dizer mobilizações) que se propõem no texto para os profissionais, relacionadas à exclusão social em bibliotecas públicas. 


\section{Fenomenologia}

Se partirmos do pressuposto de que a epistemologia é um campo da filosofia que dá conta da ciência, do ato de conhecer, da origem deste conhecimento, podemos considerar que a fenomenologia é uma representante expressiva da filosofia no contexto científico e sua consolidação reafirma a relevância da reflexão filosófica para o âmbito da ciência. $\mathrm{O}$ pesquisador, ao adotar uma postura fenomenológica, necessariamente, propõe para si e para quem comunica suas pesquisas um retorno ao pensar filosófico, o estabelecimento de uma relação particular de contemplação e aprofundamento de seu objeto de estudo. Oportuniza o filosofar e uma perspectiva filosófica, mesmo para os que não são filósofos.

Esta introdução se justifica, pois, a perspectiva filosófica é fundamento e parte essencial de uma fenomenologia que, na contramão de vários equívocos conceituais e abordagens diferenciadas para o termo, se quer considerar rigorosa. Edmund Husserl, portanto, no final do século XIX, ao dar conteúdo novo a uma palavra antiga, concebeu à fenomenologia o caráter de uma filosofia nova com potencial para se tornar uma ciência rigorosa ao propor uma impulsão filosófica originária da própria realidade e não da opinião dos filósofos. A filosofia, na fenomenologia, parte de uma experiência comum (do mundo da vida), com assuntos que dizem respeito a todos, em detrimento de visões particulares de mundo advindas de uma “individualidade genial.” (DARTIGUES, 2008).

O conhecimento humano se funda em sua experiência e dela deriva o próprio conhecimento. (LOCKE, 2000). Com relação à relevância da experiência para o conhecimento, pode-se ter uma impressão de que Locke e Husserl partilhavam da mesma ideia em suas teorias sobre o conhecimento. Locke (2000) rompe com o pensamento do inatismo (crença de que o homem possui ideias inatas que se encontram em sua alma desde que nasceu e que não derivam de experiência) em seu 'Ensaio acerca do entendimento humano'. Entretanto, suas ideias ainda estão sob o domínio da tradição cartesiana, onde a consciência é uma consciência própria, fruto de suas próprias ideias. Incluindo a experiência como algo fundamental, assim como Locke, Husserl com sua fenomenologia vai além e propõe uma dinâmica diferente para a consciência das coisas a partir das experiências, incluindo o conceito de intencionalidade que carece contextualização.

Husserl parte da ideia de que, estando concentrados sobre seus objetos, deixamos de perceber os "atos subjetivos da experiência" em si mesmos. Para que estes sejam evidenciados 
deve-se modificar a atitude ingênua, uma postura que temos diante destes objetos, através de um ato específico de reflexão. O que aparece na reflexão é o objeto intencional, que determina que toda experiência não é caracterizada apenas pelo fato de que existe uma consciência, mas é simultaneamente determinada pelo objeto intencional do qual se tem consciência. (SCHUTZ, 2012, p. 70).

A intencionalidade em fenomenologia, como distingue bem Sokolowski (2012), não está ligada ao uso comum que é feito do termo, não está ligada à teoria da ação humana, mas à teoria do conhecimento. Através da análise intencional somos direcionados para a concepção da relação entre consciência (o eu, que pensa) e o objeto, já que a consciência é sempre consciência de alguma coisa e objeto é sempre objeto para a consciência. Essa dinâmica delimita o campo de análise da fenomenologia, que é a elucidação da essência desta co-relação. (DARTIGUES, 2008). Existe, portanto, uma interdependência de sentidos entre consciência e objeto e sem isso pode-se dizer que não há nem consciência nem objeto. Fenomenologicamente, Sokolowski (2012) afirma que mente e mundo são correlatos entre si, através da intencionalidade da consciência, reivindica-se um sentido público do pensamento, raciocínio e percepção - diferente da visão cartesiana.

$\mathrm{Na}$ fenomenologia o mundo é fenômeno. A atitude fenomenológica pressupõe um desprendimento da atitude natural para, de modo reflexivo, concentrar-se nesse mundo da atitude natural (SOKOLOWSKI, 2012). Neste sentido, para o melhor entendimento de como a fenomenologia trabalha com seu objeto de estudo, auxilia uma explicação breve sobre o método de redução fenomenológica, possível através da análise intencional.

$\mathrm{Na}$ redução fenomenológica, a realidade da vida cotidiana e o senso comum (que compõem as crenças chamadas ingênuas) são colocados em parênteses. É um esforço de controle da mente para refrear os juízos e as opiniões naturais, sobrando, portanto, a "completude concreta do fluxo de nossa experiência que contém todas as nossas percepções, reflexões, em suma, nossas cogitações.” (SCHUTZ, 2012, p. 71). Portanto, a análise intencional como Husserl propõe só é possível se a consciência suspende a crença ingênua, para se colocar como um desdobramento do campo original da intencionalidade, o que Husserl chama de atitude fenomenológica (DARTIGUES, 2008).

O empenho da fenomenologia será o de analisar as vivências intencionais da consciência para perceber como nelas se produzem o sentido dos fenômenos, o sentido desse fenômeno global que se chama mundo. Metaforicamente, trata-se de distender o tecido da consciência e 
do mundo para tornar aparentes seus fios, tão finos que não apareceriam na atitude natural. (DARTIGUES, 2008).

Levando em consideração que os fenômenos se nos dão mediante nossa experiência, e esta nós experimentamos mediante os sentidos (eu sinto) em um mundo que é comum a todos os sujeitos, mundo este denominado por Schutz de "mundo da vida", um componente que se demonstra fundamental para a fenomenologia é a intuição. Kant (2000, p. 71) em sua obra 'Crítica da Razão Pura', também estabeleceu um papel de relevância para os sentidos, esboçando alguns paralelos com a filosofia fenomenológica ao destacar que "pela sensibilidade nos são dados objetos e apenas ela nos fornece intuições”.

Esta relevância que é concedida ao sujeito e para suas experiências e sensações, revela um método subjetivo pautado no ser, um ser que está neste mundo da vida compartilhado com outros seres e interagindo nele. $\mathrm{O}$ ato de reflexão constitui um momento específico desta vida compartilhada. Schutz (2012) destaca que podemos conceber as ações humanas como processos conscientes que, no curso de sua vida, enquanto age e pensa, o ego vive no nível da consciência espaçotemporal. A reflexão consiste num tipo especial de atitude, onde há uma interrupção do fluxo da duração para o exercício da consciência deste fluxo.

As ideias de reflexão pressupõem a atenção (LOCKE, 2000). Se no ato de reflexão volto minha atenção para minha experiência de vida, eu já não vivo simplesmente naquele fluxo de duração. As experiências são apreendidas, distinguidas, colocadas em relevo, diferenciadas entre si, se tornam objetos de atenção e o ato de atenção pressupõe esta experiência transcorrida. No seu transcorrer as experiências se fundem umas nas outras, são diferentes das experiências que estão no passado, que não são apreendidas enquanto vivenciadas, mas mediante um ato posterior de atenção (SCHUTZ, 2012).

Através do ato de atenção, a recordação retira a experiência do fluxo irreversível da duração, modificando a consciência, tornando-a memória. A possibilidade de recuperar algo pela memória é, de fato, um pré-requisito para a construção racional, já que o que é irrecuperável só pode ser vivido no fluxo de duração, mas não "pensado" (SCHUTZ, 2012).

Pode-se atribuir, a partir daqui, o lugar relevante da memória no cenário fenomenológico e sua relação com a fenomenologia como uma faculdade que permite a lembrança das percepções já experimentadas. Revivemos a experiência com os objetos de nossa interação em determinado tempo passado, o que Sokolowski (2012), esclareceu como a 
recuperação de parte antiga de nossa vida intencional, um reviver de uma percepção, que trazem novas dimensões para o objeto e para o sujeito.

\section{Memória}

A memória é o registro dos dados da percepção, da experiência e do conhecimento. Através da preservação destes elementos, permite a lembrança de algo pertencente ao passado possibilitando sua comparação com o presente, permitindo sua utilização para a elaboração de experiências individuais, para o conhecimento de natureza científica, filosófica ou técnica. A memória (associada à imaginação) dialoga com a temporalidade e transcende o tempo presente. Sem ela, o homem, vive um eterno presente, não seria possível o acordo nem contrato, pois estes não seriam mantidos ou cobrados, não haveria aliança ${ }^{2}$ entre os homens, o que proporcionaria o desaparecimento dos elos sociais e da própria noção de sociedade. A memória é o "princípio de todo fundamento e transmissão cultural" e o homem, "dotado de tais faculdades, espelha-se em si mesmo, lembra e prevê” (CRIPPA, 2010, p. 81).

A memória se constituiu memória antes da escrita, mas através desta última, a memória passa a fazer parte da história, partindo da premissa de que a história se fez história depois da escrita. Antes dela, pré-história. É possível estabelecer relações significativas entre memória e história importantes para este texto.

Flusser (2010) em sua obra 'A escrita: há futuro para a escrita?' destaca que antes da escrita, as coisas ocorriam, não havia uma consciência para perceber o acontecimento, o que só passou a existir com a escrita, que trouxe a consciência histórica, tornando possíveis os acontecimentos. $\mathrm{O}$ avanço do escrever em direção aos fundamentos da memória e em direção ao mundo objetivo sem as representações por imagens é a própria história ${ }^{3}$ (FLUSSER, 2010). Em consonância com Flusser, Crippa (2010) destaca que antes da escrita, nas sociedades não históricas, havia uma memória que privilegiava a lembrança atemporal, ligada aos mitos que perpetuavam determinadas experiências. Entretanto, é nas sociedades onde a escrita está presente que pode haver a opção pela história em sua leitura cronológica e documentária.

\footnotetext{
${ }^{2}$ Neste ponto do texto podemos fazer um parêntese para rememorar uma ideia, trazida na bíblia, de que a Igreja é a aliança entre Deus e os homens. A Igreja é, ela mesma, um instrumento de memória.

${ }^{3}$ Podemos identificar nessa afirmativa de Flusser com relação à escrita como objeto de observação, uma postura fenomenológica quando do agir consciente, sem estar no fluxo de duração.
} 
A história é para o homem, a história do mundo, logo, sua própria história, revelada aos que estão presentes no mundo e aos do porvir. Pode-se perceber que as pessoas pelo escrever, se sentem 'fazendo história', 'celebram' e nutrem uma sensação de perpetuação e justificação de sua existência. Isso se revela em uma crença popular de que na vida devemos plantar uma árvore, gerar um filho e... escrever um livro.

Através desta relação estreita entre escrita e memória - ao qual pelo poder da articulação de pensamentos e da escrita, já estabeleci - percebe-se também, como destaca Crippa (2010), uma relação (silenciosa) entre memória e limite, entre memória e morte. A autora destaca que a transferência da memória oral para a escrita significa que a escrita pode limitar os danos provocados pela morte, através do desaparecimento do portador da memória. Além disso, a escrita também possibilita um acúmulo maior da experiência, um acúmulo maior de informações.

De acordo com este raciocínio formulado até aqui, podemos afirmar que a escrita fortaleceu o potencial da memória em dois grandes pontos: extrapolou os limites impostos pela morte ao homem e possibilitou o acúmulo de conhecimento. Neste sentido, Crippa (2010) relembra a obra 'Fedro', de Platão, onde ele atribui a invenção da escrita a Toth, deus egípcio da morte. Nesta história, a escrita é relatada como superior às outras dádivas, pois aprimorando a sabedoria e a memória de maneira sem precedentes, perpetua a vida do autor por ultrapassar limites de tempo e espaço.

Para melhor compreensão com relação à relevância da relação entre memória e acúmulo de conhecimento, a autora relembra a estrutura social da Grécia antiga, onde a riqueza das cidades-estados estava fundamentada na propriedade fundiária e cuidar dos negócios e da casa era uma necessidade, constituindo-se contexto de uma esfera da vida privada (oposto da vida pública). A atividade na vida pública, nesta estrutura social, se resume à atividade política, portanto, a liberdade se alcança quando a esfera das necessidades não impede a atividade pública, ou seja, não impede o exercício da política. Na cidade o homem pode exercer sua liberdade através da atuação no espaço público, através da política (permissão não concedida às mulheres e escravos que são do âmbito das necessidades, bens considerados do âmbito privado, não da esfera pública). Estes homens, livres, através do exercício político na cidade, disputam poderes através do logos, da palavra, o sopro divino da mente, também traduzido como conhecimento. Sua palavra é, portanto, conhecimento racional. Esta palavra transformase em palavra pública, política, do armazém da memória e, quanto mais conhecimento 
armazenado na palavra deste homem, maior sua capacidade de convencer e atuar no espaço público. Desta dinâmica nasce a retórica (a arte de convencer), base do discurso racional e fundamento da política (CRIPPA, 2010).

O discurso complexo e com o direcionamento para o convencimento, o discurso oral, característico da retórica, exigia muita memória, era composto por partes memorizadas. Com a escrita, surge uma nova forma de memória coletiva, de memorização palavra por palavra, extranarrativa, é um aspecto de uma nova organização do saber (CRIPPA, 2010). Como podemos perceber, em diversos períodos da história da humanidade, como bem destaca Flusser (2010), uma questão de técnica, nunca é somente uma questão técnica e uma consciência em processo de transformação pede por técnicas inovadoras e esta, por sua vez, transforma a consciência.

A possibilidade do acúmulo de conhecimento proporcionada pela escrita como instrumento de memória, possibilita a coexistência de múltiplas experiências e percepções, múltiplas "intenções", com alcance que a tradição oral não poderia oferecer. Não é de se espantar que ao longo da história, as bibliotecas estivessem ligadas às políticas de confinamento ou destruição. A escrita, como instrumento de memória, transcende espaço e tempo mantendose parte de seu contexto histórico. A partir do conhecimento das experiências e percepções de outros, não estamos limitados as nossas experiências e percepções e experiências e percepções de outros, com quem nos relacionamos no mundo da vida.

O mundo da vida é um mundo social, um mundo dado, com um estoque de conhecimento já existente. O homem da era escrita, é um homem que faz e relata a história, consegue transcender espaço e tempo, tem sua consciência transformada permanentemente por este processo e pode perceber ao longo do tempo estas mudanças. Pode-se afirmar que este homem, através da história/escrita, desenvolveu um mecanismo aprimorado de memória que possibilita maior consciência, maior liberdade, maior condição de atuação, de intervenção no espaço público e privado do mundo da vida.

Relacionando à fenomenologia, Sokolowski (2012) destaca que através da recordação podemos recuperar uma parte de uma vida intencional, a revivificação de uma experiência. Portanto, em relação àqueles aspectos levantados por Crippa sobre a memória, a transcendência da morte e acúmulo de conhecimento, sob a perspectiva fenomenológica, a memória nunca é uma lembrança onde o sujeito está passivo, só rememorando. Na atitude fenomenológica, somos espectadores quando restabelecemos coisas na memória, mas não mero espectadores, já 
que estamos engajados no que aconteceu através de nossa interação como objeto da lembrança (SOKOLOWSKI, 2012) que só tem sentido, e nós também, em função desta interação.

\section{Reflexões para profissionais atuantes em bibliotecas}

Na perspectiva fenomenológica, a memória permite a revivificação das ideias de uma vida intencional, além do resgate do estoque de conhecimento que é enriquecido permanentemente (advindos das experiências e percepções das mesmas). Com relação à memória, estas duas questões foram destacadas no texto: a transcendência dos limites impostos pela morte (através da transcendência do tempo, já que podemos reviver as experiências e percepções) e a possibilidade do acúmulo de conhecimento. Esse conhecimento, como se tomou por base na história grega, perpassou a tradição oral até a escrita. Iniciando na tradição oral, alcançou toda sua complexidade na retórica que era o instrumento de exercício do poder, da atividade política, da cidadania, exercício de convencimento. Logo, a memória propiciou tudo isso. Podemos conceber que a memória inaugura o pensamento racional. O que não pode ser lembrado inviabiliza o pensamento, logo, inviabiliza a reflexão.

Ligada ao exercício da reflexão, pois que a viabiliza, rememorar é refletir para evitar a "morte" e para acumular mais conhecimento no baú de memórias das gerações vindouras. A "morte" de determinada ideia é sua não existência em si, já que não fará parte da memória, logo, não poderá ser revivida. O registro na memória é, ao contrário, sua permanência e a possibilidade de incremento dessas ideias, a possibilidade de interagir com elas, modificá-las no âmbito do mundo da vida.

Iniciei o texto com a pergunta "Qual o limite da nossa fuga?" dirigida aos profissionais atuantes em bibliotecas, principalmente os de biblioteca pública, como um alerta a papéis sociais que deveriam assumir para poder atuar politicamente. Estendo a pergunta direcionandoa para questões de exclusão enfrentadas por usuários de bibliotecas públicas nestes ambientes. A biblioteca pública não exclui, ao contrário, sua natureza é inclusiva. Portanto, o paradoxo da exclusão nestes ambientes está colocado como discussão, ainda que não como tema central, mas figurando, lá e cá, em diversos estudos (ALMEIDA JÚNIOR, 1997a; ALMEIDA JÚNIOR, 1997b; CASTRILLÓN, 2011; MACHADO, 2008; SILVA, 2011).

A era que vivemos hoje diferencia-se de outras que a sucederam em virtude do fluir do conhecimento, que toma a frente, predomina, define a era atual, tornando o próprio 
conhecimento e seu fluxo - a informação - um modo de produção material. (SOUZA, 2002). Neste contexto, Castrillón (2011) enfatiza a necessidade de bibliotecas capazes de apoiar a formação cívica e cidadã, que ofereçam um acesso à informação real e universal, capaz de salvar vidas e garantir às pessoas uma vida mais digna. Bibliotecas, que se convertam primeiramente em “meios contra a exclusão social” (CASTRILLÓN, 2011, p. 36).

Tais ideias colocam as bibliotecas públicas como um meio capaz de propiciar ao cidadão ultrapassar alguns obstáculos que o impedem de alcançar melhor qualidade de vida na sociedade pautada no conhecimento. Essa afirmativa também aparece no discurso de acesso livre e gratuito à informação para todos, sem distinções ou prerrogativas. A $\operatorname{IFLA}^{4}$ e a $\mathrm{UNESCO}^{5}$, duas entidades que se colocam em defesa dos interesses coletivos e da cidadania, ao criar o Manifesto sobre as Bibliotecas Públicas, a definiram como o centro local de informação, responsável por tornar acessível a quem utiliza o conhecimento e a informação. $\mathrm{O}$ Manifesto ressalta ainda que o trabalho desenvolvido por este mecanismo do aparelho estatal deve estar fundado na igualdade de acesso, sem qualquer distinção, seja "de idade, raça, sexo, religião, nacionalidade, língua ou condição social" e seu acervo e serviços devem estar disponíveis a todos incluindo "pessoas deficientes, hospitalizadas ou reclusas" (FEDERAÇÃO INTERNACIONAL DE ASSOCIAÇÕES DE BIBLIOTECÁRIOS E INSTITUIÇÕES, 1994).

A biblioteca pública é parte de uma estrutura de Estado com grande potencial de promoção do desenvolvimento dos indivíduos e da sociedade, bem como, do fortalecimento de valores como a igualdade social. Se não consegue se estabelecer desta forma ou ser percebida pelos cidadãos como instrumento de cidadania, isto exige um "olhar" mais atento. A quem cabe esta questão? Embora estejam inseridos em uma estrutura complexa de Estado, os profissionais atuantes nestes espaços figuram como elementos protagonistas neste contexto e são coresponsáveis na criação de políticas públicas de acesso à informação e cultura, bem como, pelas posturas e práticas que adotam ou acatam.

A exclusão nas bibliotecas públicas é um problema real, acontece permanentemente e pode se manifestar de diversas formas: através do estabelecimento de horários de atendimento inacessíveis a determinados grupos sociais; no distanciamento geográfico de parte da população; na composição de critérios inadequados para composição do acervo; na proposição de serviços e políticas voltadas para somente para grupos específicos; no atendimento

\footnotetext{
${ }^{4}$ Federação Internacional das Associações de Bibliotecários e Instituições

${ }^{5}$ Organização das Nações Unidas para a Educação, a Ciência e a Cultura
} 
diferenciado a usuários em virtude de alguma característica pessoal, social ou econômica; entre outros.

Ao convidar para esta questão o elemento memória na perspectiva fenomenológica, resgatamos a ideia de rememorar o discurso já registrado de pessoas que se sentem excluídas de ambiente de bibliotecas públicas. Este registro revela uma atitude de interação social que parece desprezar a ideia do elemento humano como o mais relevante para a biblioteca pública. Essa recordação, além de revivificar estas pessoas, é capaz de dar início à construção de um conhecimento sobre o fenômeno, já que a questão ainda não está colocada como questão central para reflexão.

Podemos crer que rememorar estas ideias e produzir mais conhecimento sobre a questão da exclusão social nos ambientes da biblioteca pode modificar uma situação? Será que conhecer as percepções e condições dos que se sentem excluídos, no tocante ao seu direito de freqüentar a biblioteca pública, pode promover mudanças? Qual o limite da nossa fuga? Será tão extenso quanto se constitui indiferença ou, melhor, será extrapolado à medida do rompimento com a ignorância tão pregada pelo profissional em questão como mal que seu trabalho pode combater? Pensando ser uma questão ainda oculta e, quando então munidos de consciência do fato, poderão os profissionais atuantes em bibliotecas utilizar este conhecimento para o exercício ético-político de participação na vida pública, como pretendiam os gregos? 


\section{Considerações finais}

Quando não conseguimos resgatar algo que precisamos de algum "arquivo" de memória, dependendo do quanto precisamos daquela "recordação", nos sentimos perdidos, sem orientação, ou mesmo, sem mecanismos para dar um passo seguinte. Ou seja, a falta de memória pode muito bem imobilizar. A memória, outrossim, pode constituir um dos mecanismos eficazes de ação por representar um conhecimento que é revivificado, dotado de sentido, de certa forma, "rehumanizado", porque um conhecimento é sempre um conhecimento construído por alguém sobre um determinado objeto, em uma interação intencional.

Mas se algo nem faz parte de nossa memória? Jaz morto, não existe, portanto, não nos ocupamos dele. Entretanto, trazer à tona o tema através da reflexão escrita, é a possibilidade de torná-lo história. Vez por outra, poderemos trazê-lo à memória em meio a tantas outras questões urgentes para a cultura em nosso país, uma forma de, ao longo do tempo, conferir uma nova visão de biblioteca pública, um novo direcionamento nas políticas instituídas nestes espaços baseadas no humano.

O exercício de reflexão é convite feito a todos, entretanto, por todos pode não ser, de igual forma, aceito. Para fazer um contraponto - e neste momento não estou falando musicalmente - talvez, ao pensar nas fugas de Bach para a pergunta feita inicialmente, estivesse exercendo eu mesma uma fuga para assuntos incômodos, uma permissão que me é concedida ao entrar pela porta da inutilidade e do devaneio da arte. Paradoxalmente, a arte, com sua inutilidade, é manifestação humana do homem que se encontra neste mundo, que compartilha o mesmo mundo com outros, por estes outros é afetado e também os afeta - portanto, abrem-se mil possibilidades de diálogo e de relações nesta humanidade representada pela arte. E ela, com sua inutilidade e ludicidade, termina por me confrontar a questionar as realidades. 


\section{Referências}

ALMEIDA JÚNIOR, O. F. Bibliotecas públicas e bibliotecas alternativas. Londrina: Ed. UEL, 1997a.

Sociedade e biblioteconomia. São Paulo: Polis; APB, 1997b.

CASTRILLÓN, S. O direito de ler e escrever. São Paulo: Pulo do Gato, 2011.

CRIPPA, G. Memória: geografias culturais entre história e ciência da informação. In:

MURGUIA, E. I. (Org). Memória: um lugar de diálogo para arquivos, bibliotecas e museus. São Carlos: Compacta, 2010. p. 79-110.

DARTIGUES, A. O que é a fenomenologia? São Paulo: Centauro, 2008.

FEDERAÇÃO INTERNACIONAL DE ASSOCIAÇÕES DE BIBLIOTECÁRIOS E INSTITUIÇÕES. Manifesto da UNESCO sobre as bibliotecas públicas. 1994. Disponível em: <http://www.ifla.org/VII/s8/unesco/port.htm>. Acesso em: 23 ago. 2011.

FLUSSER, V. A dúvida. São Paulo: Annablume, 2011.

A escrita: há futuro para a escrita? São Paulo: Annablume, 2010.

KANT, I. Crítica da razão pura. São Paulo: Nova Cultural, 2000.

LOCKE, J. Ensaio acerca do entendimento humano. São Paulo: Nova Cultural, 2000.

MACHADO, E. C. Bibliotecas comunitárias como prática social no Brasil. 2008. 184 f. Tese (Doutorado em Ciência da Informação) - Escola de Comunicações e Artes, Universidade de São Paulo, São Paulo, 2008.

SCHUTZ, A. Sobre fenomenologia e relações sociais. Petrópolis: Vozes, 2012.

SILVA, A. C. P. O. É preciso estar atento: a ética no pensamento expresso dos líderes de bibliotecas comunitárias. 2011. 358 p. Dissertação (Mestrado em Ciência da Informação) Programa de Pós-Graduação em Ciência da Informação, Universidade Federal de Santa Catarina, Florianópolis, 2011.

SOKOLOWSKI, R. Introdução à fenomenologia. 3. ed. São Paulo: Loyola, 2012.

SOUZA, F. C. Ética e deontologia: textos para profissionais atuantes em bibliotecas. Florianópolis: Ed. da UFSC; Ed. da Univali, 2002. 